\title{
Synchronized Changes in Serum Vascular Endothelial Growth Factor during the Clinical Course of Chronic Systemic Capillary Leak Syndrome
}

\author{
Yoshiaki Kinoshita, Shunji Kasaoka, Motoki Fujita, Chiyomi Oshima, Yoshikatsu Kawamura, \\ Ryosuke Tsuruta and Tsuyoshi Maekawa
}

\begin{abstract}
Systemic capillary leak syndrome (SCLS) is a rare disease characterized by leakage of plasma from blood vessels into the interstitial space due to increased capillary permeability. We describe a 24-year-old man who was hospitalized with systemic edema, hypoalbuminemia, and disseminated intravascular coagulation. After extensive investigative procedures, he was diagnosed with chronic SCLS and made a gradual recovery after starting on prednisolone, terbutaline, and theophylline. We measured the patient's serum vascular endothelial growth factor (VEGF) over time and found a relationship between serum VEGF and the clinical course.
\end{abstract}

Key words: systemic capillary leak syndrome, vascular endothelial growth factor, prednisolone, terbutaline, theophylline

(Inter Med 49: 791-794, 2010)

(DOI: 10.2169/internalmedicine.49.2929)

\section{Introduction}

Systemic capillary leak syndrome (SCLS) is a rare disease characterized by leakage of plasma from blood vessels into the interstitial space, caused by an increase in capillary permeability $(1,2)$. This shift of plasma is reported to cause multiple organ failure and lead to death during the initial capillary leak phase (3). Among the numerous mediators associated with vascular permeability, one of the most important is vascular endothelial growth factor (VEGF) (4). VEGF was reported to increase in diseases such as solid tumor, malignant lymphoma, acute myeloid leukemia, POEMS (acronym for polyneuropathy, organomegaly, endocrinopathy, M-proteins, and skin change) syndrome, and burns $(4,5)$. We report a case of chronic SCLS in which the serum VEGF level was measured.

\section{Case Report}

A 24-year-old man was transferred to our emergency department with systemic edema, hypoalbuminemia, and dis- seminated intravascular coagulation (DIC). He had been admitted to another hospital the previous day, complaining of flu-like symptoms, systemic edema, and diarrhea that had continued for over 7 days. It was his first episode of these symptoms.

Physical examination was performed on admission and revealed the following: height, $170 \mathrm{~cm}$; body weight, $72.5 \mathrm{~kg}$ (which had increased by $7.5 \mathrm{~kg}$ over the previous 10 days); pulse rate, 80 beats/min; blood pressure, $146 / 90 \mathrm{mmHg}$; respiratory rate, $24 / \mathrm{min}$; and body temperature, $37.5^{\circ} \mathrm{C}$. Laboratory data obtained on admission are listed in Table 1. Ultrasonography and computed tomography showed only bilateral pleural effusion and ascites. No cardiac, infectious, inflammatory, or malignant cause could be identified by further examinations including bone marrow puncture, colonoscopy, and cytological analysis of ascites and pleural effusion. After extensive diagnostic procedures, the diagnosis of SCLS was made.

The patient's clinical course is shown in Fig. 1. The patient was presumed to have intravascular dehydration on admission, intravenous fluid with $5 \%$ albumin was started to maintain urine output $(0.5-1.0 \mathrm{~mL} / \mathrm{kg} / \mathrm{hr})$. Between the $1 \mathrm{st}$ 
Table 1. Laboratory Data on Admission

\begin{tabular}{|c|c|c|c|c|c|}
\hline \multicolumn{2}{|l|}{ Peripheral blood } & \multicolumn{2}{|l|}{ Coagulation } & \multicolumn{2}{|c|}{ Urinalysis } \\
\hline White blood cell count & $8020 / \mathrm{mm}^{3}$ & Prothrombin time & $48.1 \%$ & Sugar & $(-)$ \\
\hline Neutrophil & $84.5 \%$ & Activated partial thromboplastin time & $35.9 \mathrm{sec}$ & Protein & (11) \\
\hline Eosinophil & $1.0 \%$ & Fibrinogen & $409 \mathrm{mg} / \mathrm{dL}$ & Occult blood & $(3+)$ \\
\hline Red blood cell count & $395 \times 10^{4} / \mathrm{mm}^{3}$ & Fibrin degradation products & $150 \mathrm{mg} / \mathrm{dL}$ & Ascitcs & \\
\hline Hemoglobin & $11.5 \mathrm{~g} / \mathrm{dL}$ & Antithrombin-III & $53.3 \%$ & White blood cell count & $94 / \mathrm{mm}^{3}$ \\
\hline Hematocrit & $31.5 \%$ & Serology & & Albumin & $1.2 \mathrm{~g} / \mathrm{dL}$ \\
\hline Platelet & $11.1 \times 10^{4} / \mathrm{mm}^{3}$ & C-reactive protein & $21.81 \mathrm{mg} / \mathrm{dL}$ & Lactate dehydrogenase & $57 \mathrm{IU} / \mathrm{L}$ \\
\hline Biochemistry & & $\operatorname{Ig} G(870-1700)^{*}$ & $652 \mathrm{mg} / \mathrm{dL}$ & Adenosine deaminase & $6.1 \mathrm{IU} / \mathrm{L}$ \\
\hline Total protein & $4.8 \mathrm{~g} / \mathrm{dL}$ & $\operatorname{Ig} A(110-410)^{*}$ & $90.2 \mathrm{mg} / \mathrm{dL}$ & TB-PCR & Negative \\
\hline Albumin & $1.7 \mathrm{~g} / \mathrm{dL}$ & $\operatorname{Ig} M(33-190)^{*}$ & $24.0 \mathrm{mg} / \mathrm{dL}$ & Culture & \\
\hline Blood urea nitrogen & $46 \mathrm{mg} / \mathrm{dL}$ & $\operatorname{Ig} \mathrm{E}(0-120)^{*}$ & $74 \mathrm{mg} / \mathrm{dL}$ & Blood & Negative \\
\hline Creatinin & $2.04 \mathrm{mg} / \mathrm{dL}$ & Antimuclear antibody & Negative & Plcural cffusion & Negative \\
\hline Total cholesterol & $102 \mathrm{mg} / \mathrm{dT}$ & Immunnelectrophoresis & None & Ascites & Negative \\
\hline $\mathrm{Na}$ & $137 \mathrm{mEq} / \mathrm{L}$ & CH $50(30-60)^{*}$ & $51.1 \mathrm{JJ} / \mathrm{mT}$. & & \\
\hline $\mathrm{K}$ & $4.9 \mathrm{mFq} / \mathrm{T}$ & Complement C3 $(65-135)^{*}$ & $103 \mathrm{mg} / \mathrm{dL}$ & & \\
\hline $\mathrm{Cl}$ & $109 \mathrm{mEq} / \mathrm{L}$ & Complement $\mathrm{C} 4(13-35)^{*}$ & $21.9 \mathrm{mg} / \mathrm{dL}$ & & \\
\hline
\end{tabular}

and 4th hospital days, he often went into shock status characterized by hypotension and hypouresis. On the 12th hospital day, his clinical course gradually worsened, with signs and symptoms of dehydration. The infusion volume increased to 5,000 mL/day, and body weight reached $91 \mathrm{~kg}$ (a weight gain of $26 \mathrm{~kg}$ ). Therefore, a regimen of prednisolone (PSL) (50 mg/day i.v.), theophylline (400 mg/day i.v.), and terbutaline $(8 \mathrm{mg} /$ day p.o.) was started on the 12 th hospital day. After the start of the therapy, the fluid volume required to maintain urine output decreased. PSL administration was reduced gradually. The patient's body weight normalized on the 30th hospital day and he was transferred to our affiliated hospital on the 38th hospital day.

We collected arterial blood samples on the 1st, 2nd, 8th, 12th, 16th, 27th, and 38th hospital days and measured serum VEGF levels by enzyme-linked immunosorbent assay (ELISA; Human VEGF ELISA; Ray Biotech, Atlanta, Georgia, USA). The transitional changes in serum VEGF levels are shown in Fig. 1. VEGF was the highest on admission (13.6 ng/mL; normal level, $<0.1 \mathrm{ng} / \mathrm{mL}$ ), decreasing to 3.0 $\mathrm{ng} / \mathrm{mL}$ on the 8th hospital day, but increasing to $8.9 \mathrm{ng} / \mathrm{mL}$ on the 12th hospital day. After administration of PSL, theophylline, and terbutaline, VEGF levels showed a gradual decrease that coincided with improvement in the clinical course. Serum VEGF levels showed a relationship with the clinical course, especially the infusion volume to maintain urine output.

\section{Discussion}

We encountered a case of SCLS that was treated successfully with PSL, theophylline, and terbutaline, and in which serum VEGF levels showed a relationship with the clinical course.

The clinical features of SCLS are classified as acute or chronic. The acute type is characterized by dramatic hypotensive episodes of shock lasting from 1 to 4 days (6). The chronic type is a rare variant of this syndrome in which mild attacks, characterized by weight gain and diffuse edema, last for weeks or even months (7). In the present case, laboratory findings did not show severe hemoconcentration and the capillary leak phase continued for more than 2 weeks. Based on the clinical and laboratory findings, we considered that the diagnosis in our case was chronic SCLS.

VEGF is one of the strongest mediators of vascular permeability which includes histamine, prostaglandin, kinins, thromboxane A2, serotonin, endothelins, tumor necrosis factor, and oxygen radicals $(4,8,9)$. VEGF rapidly increases the permeability of venules and small veins as a result of opening endothelial intercellular junctions $(5,10-12)$. In the present case, serum VEGF levels were elevated before the treatment with PSL, theophylline, and terbutaline and showed a relationship with the clinical course; in particular, the clinical course deteriorated with signs and symptoms of dehydration on the 12th hospital day, while the serum VEGF level showed an increase on the same day (Fig. 1). The overproduction of VEGF might be associated with SCLS, but to the best of our knowledge, few studies have monitored serum VEGF levels. Lesterhuis et al reported two cases of SCLS which showed high serum VEGF levels (9). These cases are similar to the present case in view of extraordinary high serum VEGF levels. However, this is first report in which VEGF levels showed a relationship with the clinical course under treatment. Furthermore, it is reported that VEGF rapidly increases endothelial permeability (13). Roberts and Palade reported that VEGF caused hyperpermeability that occurred within minutes of intradermal injection or topical application to muscle preparations (14). Therefore, serum VEGF level might be useful for evaluating the clinical course of SCLS. 


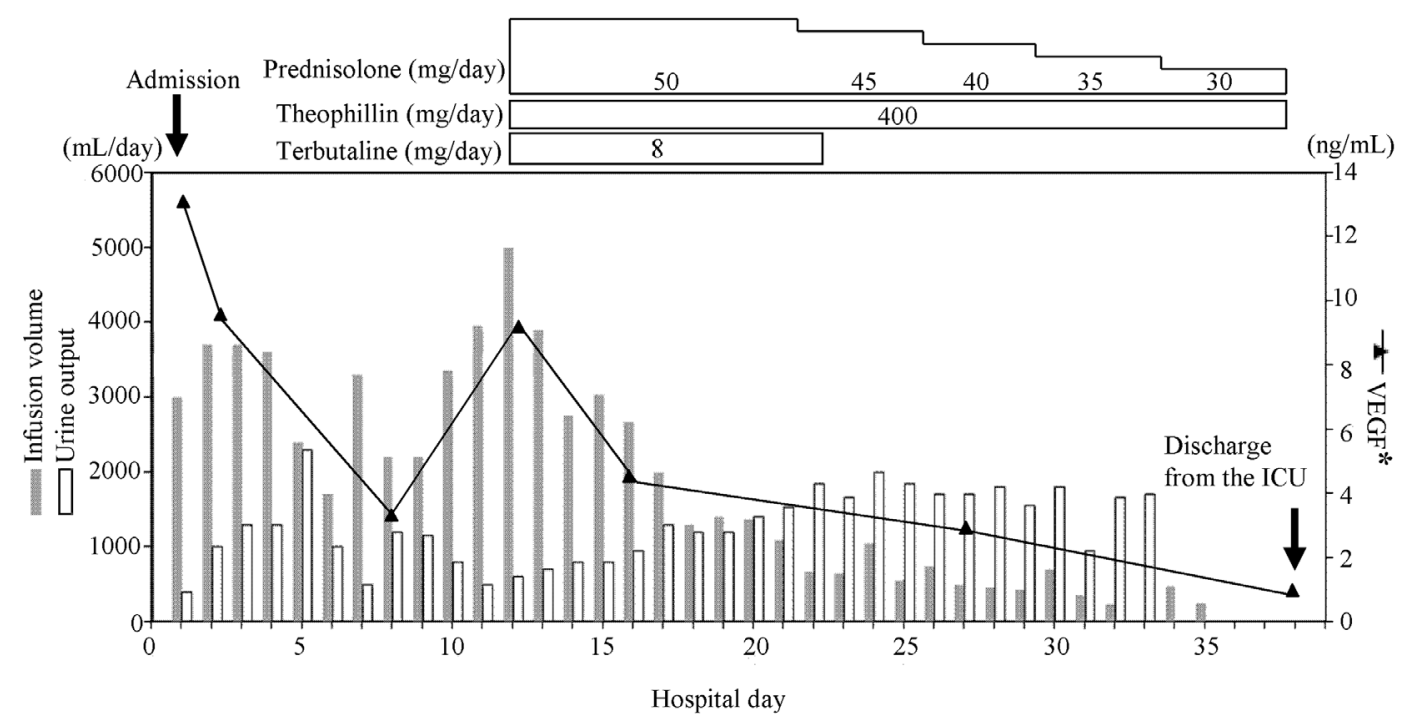

Figure 1. The transitional changes in serum VEGF levels and clinical course of the present case. Serum VEGF levels showed a relationship with the clinical course, in particular, the infusion volume to maintain urine output. *VEGF: vascular endothelial growth factor.

In fact, serum VEGF levels can be affected by several metabolic and hemodynamic factors. Experimental and clinical studies have pointed out that hypoxia increases VEGF expression (15). Peripheral tissue pressure was gained by the edema, and tissue-perfusion pressure decreased. Therefore ongoing systemic edema leads to hypoxia in peripheral tissue. Perhaps the overproduction of serum VEGF might reflect hypoxia in peripheral tissue. Furthermore, it was reported that serum VEGF was also related to cardiac contractility (16). Unfortunately, we did not measure any hemody- namic parameters except for heart rate and arterial blood pressure, so that the relationship between serum VEGF and cardiac function was unknown. Further investigation is needed to clarify the relationship between VEGF and SCLS.

In conclusion, we reported a case of SCLS successfully treated with PSL, theophylline, and terbutaline, and in which serum VEGF levels showed a relationship with the clinical course. We consider that VEGF might play an important role in SCLS, however further investigation is needed to clarify the relationship between VEGF and SCLS.

\section{References}

1. Clarkson B, Thompson D, Horwith M, Luckey EH. Cyclical edema and shock due to increased capillary permeability. Am J Med 29: 193-216, 1960.

2. Droder RM, Kyle RA, Greipp PR. Control of systemic capillary leak syndrome with aminophylline and terbutaline. Am J Med 92: 523-526, 1992.

3. Tahirkheli NK, Greipp PR. Treatment of the systemic capillary leak syndrome with terbutaline and theophylline. Ann Intern Med 130: 905-909, 1999.

4. Manfred I, Oliver S, Peter K, Sibylle G, Wolfgang E, Daniela G. Vascular endothelial growth factor serum level is strongly enhanced after burn injury and correlated with local and general tissue edema. Burns 30: 305-311, 2004.

5. Murata H, Yoshimoto $H$, Ryu $T$, et al. High fever, renal failure, disseminated intravascular coagulation and myelodysplasia accompanied with enhanced angiogenesis possibly due to overexpression of vascular endothelial growth factor. Intern Med 39: 570-575, 2000.

6. Airaghi L, Montori D, Santambrogio L, Miadonna A, Tedeschi A. Chronic systemic capillary leak syndrome. Report of a case and review of the literature. J Intern Med 247: 731-735, 2000.

7. Rauzy O, Adoue D, Arlet P. Chronic systemic capillary leak syndrome not requiring treatment? Am J Med 105: 360, 1998.

8. Atkinson JP, Waldmann TA, Stein SF, et al. Systemic capillary leak syndrome and monoclonal IgG gammopathy; studies in a sixth patient and a review of the literature. Medicine (Baltimore)
56: 225-239, 1977.

9. Lesterhuis WJ, Rennings AJ, Leenders WP, et al. Vascular endothelial growth factor in systemic capillary leak syndrome. Am J Med 122: e5-e7, 2009.

10. Hashiguchi T, Arimura K, Matsumuro K, et al. Highly concentrated vascular endothelial growth factor in platelets in CrowFukase syndrome. Muscle Nerve 23: 1051-1056, 2000.

11. Senger DR, Galli SJ, Dvorak AM, Perruzzi CA, Harvey VS, Dvorak HF. Tumor cells secrete a vascular permeability factor that promotes accumulation of ascites fluid. Science 219: 983-985, 1983.

12. Bates DO, Harper SJ. Regulation of vascular permeability by vascular endothelial growth factors. Vascul Pharmacol 39: 225-237, 2002.

13. Hippenstiel S, Krüll M, Ikemann A, Risau W, Clauss M, Suttorp N. VEGF induces hyperpermeability by a direct action on endothelial cells. Am J Physiol 274: 678-684, 1998.

14. Roberts WG, Palade GE. Increased microvascular permeability and endothelial fenestration induced by vascular endothelial growth factor. J Cell Sci 108: 2369-2379, 1995.

15. Rissanen TT, Vajanto I, Hiltunen MO, et al. Expression of vascular endothelial growth factor and vascular endothelial growth factor receptor-2 (KDR/Flk-1) in ischemic skeletal muscle and its regeneration. Am J Pathol 160: 1393-1403, 2002.

16. Iacobellis G, Cipriani R, Gabriele A, Di Mario U, Morano S. High circulating vascular endothelial growth factor (VEGF) is related to 
Inter Med 49: 791-794, 2010 DOI: 10.2169/internalmedicine.49.2929

a better systolic function in diabetic hypertensive patients. Cy- tokine 27: 25-30, 2004.

(C) 2010 The Japanese Society of Internal Medicine http://www.naika.or.jp/imindex.html 